DOI: $10.17805 /$ trudy.2019.1.6

\title{
СТАНОВЛЕНИЕ ПСИХОЛОГИЧЕСКОГО ОБРАЗОВАНИЯ И НАУЧНЫХ ИССЛЕДОВАНИЙ ПО ПСИХОЛОГИИ В САНКТ-ПЕТЕРБУРГСКОМ ГОСУДАРСТВЕННОМ УНИВЕРСИТЕТЕ: 1940-1950-е ГГ.
}

\author{
Н. А. Логинова \\ Санкт-Петербургский государственный университет
}

Аннотация: В послевоенные годы центром петербургской психологической школы становится СПбГУ. В 1944 г. впервые открывается отделение психологии под руководством Б. Г. Ананьева. В статье на основе архивных документов рассматриваются направления научных исследований кафедры.

По материалам научного доклада на конференции «Кросс-культурные и междисциплинарные исследования в истории психологии: результаты и перспективы» (Москва, 24-25 ноября 2018 г.), проведенной в рамках проекта № 18-513-18017, поддержанного РФФИ.

Ключевые слова: история петербургской психологической школы; история психологии; история советской психологии; Санкт-Петербург; Б. Г. Ананьев; В. Н. Мясищев

\section{ESTABLISHMENT OF PSYCHOLOGICAL EDUCATION AND SCIENTIFIC RESEARCH ON PSYCHOLOGY AT SAINT PETERSBURG UNIVERSITY: THE 1940s-1950s}

\author{
N. A. Loginova \\ Saint Petersburg State University
}

\begin{abstract}
In the postwar years, Saint Petersburg State University became the center of the St. Petersburg psychological school. In 1944, a psychology department was opened for the first time under the direction of B.G. Ananiev. The paper is based on archival documents and considers the department's research directions.

The research is based on the materials of the scientific reportat the conference "Cross-Cultural and Interdisciplinary Studies into the History of Psychology: Results and Prospects" (Moscow, 24-25 November 2018), held within the project No. 18-513-18017 supported by RFBR.

Keyworlds: history of St. Petersburg psychological school; history of psychology; history of Soviet psychology; Saint Petersburg; B. G. Ananiev; V. N. Myasishchev

* Работа выполнена при поддержке РФФИ (РФФИ-ОГОН) (проект «История Петербургской психологической школы (1941-1991): архивные разыскания и изучение источников», грант № 17-06-00484).

The work is supported by Russian Foundation for Basic Research; project \#17-06-00484 "History of the St-Petersburg scientific school (1941-1991): The archive seeking and research of the resources".
\end{abstract}


Научные труды Московского гуманитарного университета 2019 № 1

В 1930-е годы главным центром психологии в Ленинграде был Ленинградский педагогический институт (в настоящее время РГПУ им. А. И. Герцена), где была сильная кафедра психологии со своей историей. В научном плане выделялся и отдел психологии Института мозга им. В. М. Бехтерева. Решающим фактором такого положения явились выдающиеся ученые, которые здесь работали, те из них, кто имел программные идеи и организаторские способности, чтобы возглавить коллективные исследования. В педагогическом институте лидерами были М. Я. Басов, а после его преждевременной смерти С. Л. Рубинштейн. В Институте мозга - В. М. Бехтерев, а после него, уже в 1930-х гг. Б. Г. Ананьев и В. Н. Мясищев.

Перед самой войной расстановка научных сил несколько изменилась в связи с тем, что в 1939 г. Мясищев был назначен директором Психоневрологического института им. В. М. Бехтерева ${ }^{1}$. С 1937 г. по 1943 гг. Ананьев заведовал отделом психологии в Институте мозга. В войну Институт мозга был обескровлен. Он понес материальные и, главное, людские потери. В педагогическом институте (РГПУ) ситуация была лучше и по возвращении из эвакуации в конце 1943 г. Борис Герасимович работал в этом институте. Здесь организовал лабораторию психологии речи, продолжил линию С. Л. Рубинштейна, который уже работал в Москве.

В годы Великой Отечественной войны все силы народа были направлены на победу. Психологи участвовали в общем святом деле, погибали, получали ранения, теряли близких людей. Психологи-ленинградцы воевали на фронте, жили и работали в блокадном Ленинграде или в эвакуации. Эта часть истории Петербургской психологической школы достойна самостоятельного научного исследования (Кольцова, Олейник, 2006). В настоящей статье речь пойдет о первых послевоенных года, когда шло становление психологии в СПбГУ.

В 1943 г. по решению правительства в СПбГУ и МГУ были учреждены отделения психологии философских факультетов. В Ленинградском университете отделение открылось в 1944 г. и явилось основой не только нового психологического центра города, но и страны. В настоящем 2019 г. мы отметим 75-летие психологического образования в Петербургском университете. Это событие имеет большее значение, чем образование факультета психологии в 1966 г., потому что начало было положено тогда в конце войны. Этот исторический момент мало изучен и скупо представлен в научной литературе (Логинова, 2006, 2014, 2016, Степанова, $2003^{2}$ и др.). Цель статьи рассказать о послевоенной психологии в Санкт-Петербургском Государственном университете (СПбГУ), который в рассматриваемый период назывался Ленинградским государственным университетом (ЛГУ).

\footnotetext{
${ }^{1}$ В настоящее время это центр по неврологии и психиатрии им. В. М. Бехтерева.

${ }^{2}$ См. также: Ананьев, Б. Г. (1965) Справка о состоянии работы кафедры психологии Ленинградского университета. 03.06.65 // Домашний архив Б. Г. Ананьева.
} 
По приглашению ректора Ленинградского университета А. А. Вознесенского Б. Г. Ананьев перешел на работу в ЛГУ из Института усовершенствования учителей и педагогического института им. А. И. Герцена, где официально работал после возвращения из эвакуации. В июле того же года его назначили заведующим кафедрой психологии (Личное дело Б. Г. Ананьева // Архив СПбГУ. Дело $135^{1}$ ). Это событие открыло новую главу жизни Ананьева. Появилась возможность создать нечто новое, осуществить свой собственный замысел, свои представления о науке и образовании. Борис Герасимович всегда ставил большие цели и был готов к трудной созидательной работе.

В Ленинградском университете, в отличие от МГУ, где еще в 1912 г. был открыт челпановский Психологический институт, никогда ранее не готовили специалистов-психологов, не было психологических кафедр, лабораторий, если не считать ранней попытки А. П. Нечаева и кратковременного существования кафедры психологии в 1919-1921 гг. Да и психологов тоже не было. Учебный курс по психологии читали и философы. Но в университете были профессора естественных наук, которые проявляли непраздный интерес к психологии, а некоторые оставили выдающийся след в истории нашей науки, не будучи психологами по специальности. Среди них физиологи Н. Е. Введенский, И. П. Павлов, И. М. Сеченов, А. А. Ухтомский, химик Д. И. Менделеев и другие. Именно их материалистическую линию продолжали психологи Ленинградского университета (СПбГУ).

Создание отделения психологии в Ленинградском университете было делом огромной трудности. Этот процесс происходил в пережившем страшную блокаду городе, где был повреждена материальная база психологической науки, не хватало психологических кадров. Созидательные процессы искажались и тормозились политической обстановкой в стране и мире. Спустя два-три года после окончания Великой Отечественной войны с новой силой развернулись политические репрессии. В 1949 г. было возбуждено так называемое «Ленинградское дело», в результате которого погиб ряд крупных деятелей нашего города, в том числе ректор Ленинградского университета А. А. Вознесенский. Были и другие жуткие сталинские кампании, и любой гражданин не мог чувствовать себя в безопасности.

Вопреки всем невзгодам психологам Ленинградского университета удалось многое сделать уже в первые годы существования отделения. Дело

\footnotetext{
${ }^{1}$ Вступление в должность зав. кафедрой было поэтапным. В личном деле Б. Г. Ананьева есть указание на то, что Всесоюзный комитет по делам высшей школы утвердил его в должности 28 февраля 1945 г.

${ }^{2}$ А. П. Нечаев организовал психологическую лабораторию в Петербургском университете в 1901 г. Сами студенты потребовали, чтобы в университете их учили современной экспериментальной психологии. Однако, в то время лаборатория не прижилась. О ее истории, как и кафедры психологии, существовавшей в СПбГУ с 1919 по 1921 гг. пока мало неизвестно.
} 
Научные труды Московского гуманитарного университета

2019 № 1

в людях, в их профессиональной солидарности и самоотверженности. Ядро кафедры психологии составили бывшие сотрудники Института мозга им. В. М. Бехтерева: Б. Г. Ананьев, В. Н. Мясищев, А. В. Ярмоленко, В. И. Кауфман, Г. С. Рогинский, Н. В. Опарина, А. А. Прессман ${ }^{1}$. Так возникли персональные предпосылки для преемственной связи нового психологического центра с бехтеревской научной школой. Но еще важнее преемственность, основанная на общности принципов и подходов, среди которых в первую очередь отметим комплексность в изучении человека, объективность психологического познания, союз с естественными и общественными науками, принципы отражения, генетический принцип. Все это с самого начала было положено в основу деятельности новой кафедры и отделения психологии.

Душой всех дел был Борис Герасимович Ананьев. Он подавал пример инициативности, ответственности. Был требователен, очень много работал. Умело налаживал коллективную работу, добивался результатов от каждого ее участника. Он считал, что руководителю не пристало бояться конфликта, если он в интересах дела. Он ставил научные проблемы и инициировал циклы исследований, обращался в разные инстанции, добиваясь решения насущных организационных, исследовательских, кадровых вопросов. Ананьев много занимался психологическим просвещением населения города и руководящих партийных работников, тем самым привлекал внимание к психологии, продвигал психологическое знание в общественную практику, в жизнь каждого человека ради гуманизации общества.

В 1944 г. праздновали 125-летие университета². В мае - июне 1944 г. университет возвращался из эвакуации из Саратова. В 1944/45 учебном году на новом психологическом отделении было четверо студентов, перешедших с других факультетов сразу на третий курс, поэтому первый выпуск состоялся уже в 1947 г., причем на год раньше, чем в МГУ, были и те, кто стали учиться на отделении со второго курса.

Первые выпускники Л. М. Веккер, П. С. Россол, Е. В. Лапшина (Шорохова), Н. В. Яшкова впоследствии стали учеными, а двое - Лев Маркович Веккер и Екатерина Васильевна Шорохова, весьма заметными фигурами в советской психологии. Вместе с тем были и те, кто поступили в университет впервые. В 1948 г. был второй выпуск - всего лишь два человека: Н. А. Жулидова и Е. Безрукова (Степанова, 2003), а вот третий выпуск - 1949 года - можно считать сравнительно большим. Среди них ставшие впоследствии извест-

\footnotetext{
${ }^{1}$ Некоторые психологи, вероятно, некоторое время работали в Лгу по совместительству (Р. А. Каничева, А. А. Люблинская, А. Ц. Пуни, Л. А. Шифман).

${ }^{2}$ Незадолго до возвращения СПбГУ в Ленинград общественность отмечала 125-летие университета. Он был награжден Орденом Ленина. Торжественное заседание по случаю юбилея происходило 24 февраля 1944 г. в Саратове в оперном театре им. Н. Г. Чернышевского (История Ленинградского ..., 1969: 382). В настоящее время установлена более ранняя дата образования университета - 1724 г., когда в Петербурге был учрежден университет при Академии наук - детища Петра Первого.
} 
ными учеными Е. С. Кузьмин, И. М. Палей, Е. Ф. Рыбалко, Е. И. Степанова. В 1950 г. выпуск состоял уже из тридцати шести молодых специалистов, в том числе А. А. Бодалев, В. Н. Андреева, Л. Н. Ланда, П. Л. Горфункель.

Долгое время набор студентов был очень затруднен отсутствием информации о психологии как науке и тем более практики. Профессии как номенклатурной единицы в системе кадров вообще не было. В иные периоды прием на отделение составлял всего пять человек (например, в 1958 г.). Тем не менее, подготовка психологов не прерывалась, и к 1965 г. из стен университета вышли 336 специалистов-психологов ${ }^{1}$, из них трое к 1966 г. стали докторами наук по психологии (Ломов - в 1963 г., Веккер — в 1964 г., Бодалев - в 1965 г.) и свыше семидесяти кандидатами наук.

Системообразующим фактором и кафедры психологии, и всего отделения стала научная деятельность. Уже осенью 1944 г. психологи делали доклады на юбилейной научной сессии университета, а 5-7 июля 1945 г. состоялась первая научная конференция отделения психологии философского факультета ЛГУ. На этой конференции выступили проф. Б. Г. Ананьев, доц. А. А. Люблинская, проф. В. Н. Мясищев, проф. Г. С. Рогинский, проф. И. В. Страхов, доц. А. В. Ярмоленко, а также студент Л. М. Веккер и студентка В. Ф. Нестерова (Научная конференция..., 1945). 6 июля 1945 г. доклад «Основные проблемы психологии» сделал С. Л. Рубинштейн ${ }^{2}$.

В ноябре того же победного 1945 г. на ежегодной научной сессии Ленинградского университета на секции философии были сделаны доклады Б. Г. Ананьевым, Г. С. Рогинским, И. В. Страховым, А. В. Ярмоленко.

Борис Герасимович проявил инициативу и добился созыва Всесоюзной конференции университетов по психологии, которая и состоялась в начале октября 1947 г. на базе Ленинградского университета. Приехал из Семипалатинска профессор А. П. Нечаев, высланный туда из Ленинграда в годы довоенных репрессий. Доклад Б. Г. Ананьева « Об очередных задачах советской психологии» представил программу развития нашей науки, быть может, первую после войны.

Это событие ныне забыто и почти не замечено историками психологии, а ведь оно было довольно представительным и послужило предтечей трех последующих всесоюзных совещаний по психологии, проведенных в Москве в 1952, 1953 и 1955 гг. Приехали в Ленинградский университет психологи из Москвы, Киева, Ленинграда, Иркутска, Львова, Петрозаводска, Минска, Вильнюса, Еревана, Риги, Тарту, Горького, Свердловска, Тбилиси. Всего более 450 человек. На конференции 1947 г. были намечены пути послевоенного развития нашей науки, осознана потребность организационного оформления ее институций. Участники конференции направили пись-

${ }^{1}$ Ананьев, Б. Г. (1965) Справка о состоянии работы кафедры психологии Ленинградского университета. 03.06.65 // Домашний архив Б. Г. Ананьева.

${ }^{2}$ В опубликованных тезисах конференции доклад С. Л. Рубинштейна не значится. Возможно, он был сверхпрограммным. 
Научные труды Московского гуманитарного университета

2019 № 1

мо с обращением к министру высшего образования СССР С. В. Кафтанову о необходимости создать психологический журнал и созвать в 1948 г. в Москве Всесоюзный съезд по психологии.

Тематика и направления научно-исследовательской работы кафедры были преемственно связаны с довоенными исследованиями психологов Института мозга им. В. М. Бехтерева, Психоневрологического института им. В. М. Бехтерева, ЛГПИ им. А. И. Герцена (ныне - РГПУ). Научные исследования разворачивались по следующим направлениям: психология чувственного познания, психология личности, ее характера и самосознания, психология развития, сравнительная психология, история русской психологии, патопсихология (в этом направлении лидирующую роль играл В. Н. Мясищев). Активно проводили исследования по сравнительной психологии под руководством сначала Г. С. Рогинского, а потом Н. А. Тих. Студенты и аспиранты выезжали на практику и проводили наблюдения в Сухумском заповеднике, где был питомник обезьян.

Все студенты были вовлечены в работу кафедры. Уже осенью 1944 г. Борис Герасимович организовал научный кружок. Студенты выступали с сообщениями, завели рукописный «Вестник научно-психологического кружка» с лучшими студенческими работами и рефератами советской и иностранной литературы, с хроникой научной жизни. Студент Лев Веккер был самым зрелым среди кружковцев. Он имел собственные идеи, которые развивал всю жизнь в последующих исследованиях.

На рубеже сороковых-пятидесятых годов были приняты первые аспиранты Л. М. Веккер, А. А. Бодалёв, Е. С. Кузьмин, Б. Ф. Ломов, Е. Ф. Рыбалко, Н. В. Серебренникова. Ряд аспирантских и других научных исследований осуществлялись под знаком известной «Павловской» сессии 1950 г., что выразилось в непременных ссылках на И. П. Павлова и его сподвижников, опоре на физиологические закономерности в объяснении психических явлений. Это, в принципе, соответствует материалистическому умонастроению психологов Ленинградского университета, общему духу складывающейся научной школы, близкой естествознанию, однако при этом была опасность потерять самостоятельность психологической науки, специфику ее предмета. Эту опасность психологи поняли и противостояли ей в тяжелых исторических обстоятельствах политических кампаний и жесткого идеологического контроля на всех уровнях — от ЦК ВКП (б) до первичной партийной организации.

Современному психологу, вооруженному многообразным методическим инструментарием и безграничными информационными ресурсами интернета, те первые кандидатские диссертации могут показаться простыми по методам сбора и обработки данных, но нельзя не заметить серьезное научное содержание, добросовестность эмпирического изучения и тщательность теоретической интерпретации. К тому же всегда вызывает уважение увлеченность, ответственное честное отношение к своему делу и бескорыстие, свойственное большинству ученых. 
Несмотря на отсутствие в стране научных журналов по психологии (до 1955 г.), ограниченность издательских ресурсов, очень скоро психологи ЛГУ стали публиковать статьи о результатах исследований в серийных сборниках «Проблемы психологии» (1948), «Психология» $(1949,1954,1955)$, «Психология и педагогика» (1957), «Склонности и способности» (1962), «Проблемы общей и индустриальной психологии» $(1963$, с $1964-$ «Проблемы общей и инженерной психологии») и др. С большим воодушевлением психологи страны восприняли учреждение всесоюзного журнала «Вопросы психологии» в 1955 г., т. е. спустя более 20 лет после упразднения журнала «Психология» в 1932 г. Всего за годы существования отделения психологии было издано свыше 350 научных работ, в том числе 16 значительных монографий. Кроме упомянутых выше, вышли в свет фундаментальные книги Б. Г. Ананьева «Психология чувственного познания» (1960), «Теория ощущений» (1961), первые монографии А. А. Бодалева «Восприятие человека человеком» (1965), Л. М. Веккера «Восприятие и основы его моделирования» (1964), Б. Ф. Ломова «Человек и техника» (1963), обобщающая книга В. Н. Мясищева «Личность и неврозы» (1960), монографии Г. С. Рогинского «Навыки и зачатки интеллектуальных действий у обезьян» (1948), А. В. Ярмоленко «Очерки по психологии слепоглухонемых» (1962), коллективная монография «Осязание в процессах познания и труда» под редакцией Б. Г. Ананьева (1959) была отмечены премией им. К. Д. Ушинского Академии педагогических наук РСФСР. Эта книга - до сих пор непревзойденный научный труд по проблеме осязания. Ее в обязательном порядке изучают современные студенты факультета психологии СПбГУ.

Научная жизнь университетских психологов была насыщенной. Проводились научные мероприятия, посвященные памятным датам и значимым общественным событиям. Так, в 1945 г. отметили 125-летие со дня рождения Ф. Энгельса, в 1946 г. 75-летие со дня смерти К. Д. Ушинского, в 1957 г. 40-летие Октябрьской революции и т. п. Проходили коллективные обсуждения новых книг и рукописей. 25 марта 1948 г. на открытом заседании кафедры психологии состоялось обсуждение «Очерков истории русской психологии XVIII-XIX веков» Б. Г. Ананьева, опубликованных в 1947 г. (Шемякин, 1948), а в 1957 г. дискутировали по книге С. Л. Рубинштейна «Бытие и сознание». В 1963 г. на кафедре психологии Борис Герасимович делал доклады по материалам своей будущей книги «Человек как предмет познания» ${ }^{1}$.

В послевоенные годы, особенно при жизни Сталина в обязательном порядке всем ученым и не только им строго предписывалось участвовать в идеологических дискуссиях, с последующими оргвыводами. Так, в ходе борьбы против «вейсманизма-морганизма», «за передовую мичуринскую биологию» (1948 г.) из университета были уволены крупные биологи - физиолог Э. Ш. Айрапетьянц, генетик М. Е. Лобашев, - из библиотеки были изъяты

${ }^{1}$ Первое издание вышло в 1968 г. и было отмечено премией Ленинградского университета. В 2018 г. исполнилось 50 лет этой выдающейся книги. 
Научные труды Московского гуманитарного университета 2019 № 1

книги биолога И. И. Шмальгаузена. В 1949 г. идеологические кампании следовали одна за другой - против идеализма в физике, космополитизма в науке, формализма в литературоведении. Обязательными были публичные, устные и печатные восхваления работ Сталина по языкознанию и политэкономии и чуть ли не по всем наукам. Приходилось слушать политически выдержанные установочные доклады, выступать самим, писать статьи на все вышеупомянутые темы. Явно навязаны сверху темы докладов, например, «0 космополитизме в психологии» Б. Г. Ананьева (ЦГА, 1949) В. Н. Мясищева «О проблемах личности в трудах И. В. Сталина» (ГАНТД, 1952). Вследствие указанной кампании 1949 г. Б. Г. Ананьеву пришлось срочно сократить до двух лекций раздел программы по истории зарубежной психологии и снять зачет по этой дисциплине. Подобные мероприятия он был обязан проводить по статусу. За их исполнение строго спрашивали партийные органы, руководство факультета и университета.

После объединенной («павловской») сессии АН СССР и АМН СССР 1950 г. был поставлен вопрос о путях перестройки работы всех биологов и психологов, страны. Заведующий кафедрой Ананьев наметил ряд мероприятий: внести изменения в учебный план, заменить дифференциальную психологию на психофизиологию, организовать семинар по изучению трудов И. П. Павлова, развернуть критику и самокритику (Протокол № 1 // ЦГА СПб. Ф. 7240. Опись 14. Дело 1788).

В протоколе заседания кафедры психологии от 14 декабря 1950 г. (там же, протокол №12) содержится изложение доклада Б. Г. Ананьева о перестройке научной работы кафедры и отделения психологии на основе решений «павловской» сессии АН СССР и АМН СССР 1950 г. Борис Герасимович выступал с самокритикой и критикой. О себе говорил тогда: «Я стоял на неправильных позициях в вопросе соотношения физического и психического в проблеме ощущений», допускал-де ошибки в трактовке истории русской психологии. Укорял философов за то, что они уклоняются от обсуждения психологических проблем и публикаций. Высказывал обязательные в тот момент критические суждения в адрес опального Л. А. Орбели, но также А. Р. Лурии, В. Н. Мясищева, С. Л. Рубинштейна.

Из песни слов не выкинешь, историк обязан сказать и о таких неприятных фактах. При этом важно правильно интерпретировать их и отделить навязанные сверху оценки от собственного мнения ученого. Это относится не только к Ананьеву. В сходном положении оказывались и другие советские граждане, даже далекие от науки, философии или литературы. Если посмотреть на факты в контексте времени, учесть статус, обязывающий руководителя быть рупором официальных установок, и сравнить с тем, как Борис Герасимович относился к коллегам - объектам критики до «павловской» сессии и позже, в более вольные времена, то можно провести границу между его собственным и навязанным сверху мнением. Из совокупности высказываний Ананьева разных лет можно понять, что у него были отнюдь 
не только конъюнктурные, но и сугубо научные расхождения с некоторыми учеными. Он и в после сталинские годы был не согласен с представлением А. Р. Лурии о локализации сознания в лобных долях головного мозга. Научный характер имело его критическое высказывание в адрес В. Н. Мясищева (Протокол заседания кафедры // ЦГА СПб. Ф. 7240. Опись 14. Л. 93). Ананьев, споря с ним, считал, что отношения личности не являются первичными образованиями, но вырастают из процессов отражения мира. Мясищев возражал Ананьеву. Был обмен идеями, что является нормой научного общения. Плохо, что такое общение сковывалось внешним политическим контролем ${ }^{1}$.

Учебно-воспитательный процесс на отделении психологии имел характерные особенности, отвечающие требованиям исторического времени и духу складывающейся здесь научной школы. Повседневная учебная работа требовала постоянного внимания и заботы заведующего кафедрой и всех преподавателей. Борис Герасимович читал общую психологию, историю психологии, психологию личности, руководил многими студенческими курсовыми и дипломными работами (их количество одновременно доходило до тридцати трех!), был избран первым председателем Студенческого научного общества университета (1946 г.). Он вникал в студенческую работу. Бывало, часто сам составлял для каждого студента-психолога подробный план исследования и рекомендовал конкретные методики (по воспоминаниям В. Н. Куницыной, И. М. Палея, Е. И. Степановой (Степанова, 2003), Е. В. Шороховой), неизменно делал существенные замечания при обсуждении на кафедре аспирантских, курсовых и дипломных работ.

C самого начала был взят курс на сотрудничество со смежниками не только ученых, преподавателей, но и студентов, что соответствовало принятому в Институте мозга, откуда вышли первые преподаватели психологического отделения университета, комплексному подходу к проблемам психологии человека. Характер учебного плана тоже отражал эту междисциплинарную направленность. В учебных планах много часов отводилось на изучение естественнонаучных дисциплин, в нем в разные годы присутствовали физиология общая и органов чувств, физиология нервной деятельности, биология, дарвинизм, сравнительная психология и антропология. Разумеется, учебный план включал психологические дисциплины общую, экспериментальную, детскую, педагогическую, дифференциальную психологию, историю психологии, зоопсихологию, психопатологию или патопсихологию, психологию художественного творчества, а также историю философии, основы марксизма-ленинизма, диалектический и исторический материализм, политэкономию, всеобщую историю, историю русской литературы. К тому же проводились специальные семинары по психологии (сведения из газеты Ленинградский университет, за 12.06.1945 и протоко-

\footnotetext{
${ }^{1}$ По моим наблюдениям, в наши дни научное общение мельчает, становится малосодержательным. Причины вижу в усложнении и сильной дифференциации науки, а еще в отсутствии научных убеждений и нежелании «портить отношения».
} 
Научные труды Московского гуманитарного университета

2019 № 1

лов кафедры 1940-1950-х гг. // ЦГА СПбГУ. Ф. 7240. Описи 14 и 15) ${ }^{1}$. Ананьев побуждал поднимать на семинарах насущные проблемы науки, относящиеся к ее предмету, внушал сотрудникам и аспирантам, что семинары должны быть школой коллективного мышления.

Воспитательной работе со студентами уделяли серьезное внимание, что порой превращалось в бесцеремонное вторжение в личную жизнь взрослых уже людей, чрезмерной строгостью к их невинным шалостям и розыгрышам. Но особенно сурово наказывались студенты, осмелившиеся самостоятельно обсуждать острые философские и политические вопросы и, упаси бог, создавать неформальные кружки и общества. Уже после смерти тирана и после XX съезда, во времена «оттепели» и далее случалось, что некоторые критически мыслящие, «слишком умные» студенты, в том числе и психологи, были изгнаны из университета или посажены в тюрьму. Заступничество руководства отделения и факультета далеко не всегда помогало в таких случаях.

Несмотря на жесткие условия работы и диктат партийных начальников, руководители кафедры и отделения психологии строили организационную деятельность демократично, стремились учитывать и развивать индивидуальность студентов и сотрудников, заботились о судьбе выпускников отделения. Как явствует из протоколов заседаний кафедры, студентов старших курсов приглашали на заседания, и смело высказывали весьма критические суждения в адрес преподавателей, включая заведующего. Критиковали и учебные программы, и учебный процесс. Кто-то сетовал на то, что кадры-де слабые, все замыкается на Ананьеве, кто-то, что темы курсовых и дипломных не связаны с будущей работой, чаще говорили о нехватке экспериментального оборудования и т.д. Они не брали во внимание тех колоссальных трудностей, с которыми ежедневно сталкивается кафедра и в первую очередь заведующий. Им хотелось всего и сразу (протокол №19 от 22 марта 1951 г// ЦГА СПб. Опись 15. Дело 266). Запальчивые и не всегда справедливые студенческие речи, однако, не прерывали, всех выслушивали и предлагали студентам активнее участвовать в строительстве отделения. И студенты участвовали в общих кафедральных делах, будь то шефская помощь предприятиям, выезд в подшефный колхоз или научное исследование кафедры. Аспиранты выступали рецензентами дипломных работ, проверяли работы и участвовали в приеме экзаменах. Так формировался единый коллектив и единство научной школы.

Долгое время профессии психолог как таковой не было, и обязательное государственное распределение выпускников психологического отделения, направление их на места работы проходило трудно. Многие вынуждены были устраиваться на работу, где придется. меняли специальность, становились учителями средней школы, преподавателями философии в вузах и

${ }^{1}$ В университете наряду с психологами, предназначавшимися для работы в вузах и научных учреждениях, готовили преподавателей логики и психологии для школы (на филологическом факультете). Характер образования там был несколько другим. 
техникумах. Самые активные, партийные выпускники философского, идеологического, факультета, находили место работы в советских, комсомольских (М. Д. Дворяшина, например) и партийных органах (В. П. Кузьмин, он позже занимал значительный пост в ЦК КПСС).

Борис Герасимович как руководитель отделения много сил отдавал подбору кадров, подготовке работоспособного творческого коллектива. Он с большим трудом добивался приема на работу в университет выпускников и перспективных, нужных для общего дела ученых, не имеющих на тот момент прописки в Ленинграде (примеры переезда Л. М. Веккера из Вильнюса, М. Д. Дворяшиной из Уфы, И. М. Палея из Перми, А. Г. Ковалева из Симферополя).

В пятидесятые годы на отделении психологии впервые появились студенты из стран народной демократии - Болгарии, Венгрии, ГДР, Китая, Польши, Румынии. Некоторые из универсантов-иностранцев впоследствии стали более или менее видными деятелями марксистской психологии у себя на родине (профессора Л. Десев и К. Стоянов в Болгарии ${ }^{1}$, К. Яро и Э. Кобора в Венгрии, 3. Капустинская в Польше, К. Пуфан и В. Маре в Румынии,). Выпускники-иностранцы не забывали своих учителей. В домашнем архиве Б. Г. Ананьева сохранились адресованные ему письма из-за рубежа, в том числе от бывших выпускников, приглашения для чтения лекций в университеты. К сожалению, он так и не использовал эти возможности - был слишком занят, а потом здоровье не позволяло. Незадолго до кончины в 1972 г. Борис Герасимович собрался поехать в Берлинский университет для чтения лекций, но этому не суждено было сбыться.

В 1951 г. Б. Г. Ананьев был назначен директором ленинградским НИИ педагогики АПН РСФСР. Некоторое время, до 20 июня 1953 г. продолжал заведовать кафедрой психологии ЛГУ (вероятно, по совместительству). В начале 1953-1954 академического года заведующим стал Владимир Николаевич Мясищев ${ }^{2}$. Но Борис Герасимович не прерывал активного взаимодей-

\footnotetext{
${ }^{1}$ М. Д. Няголова пишет в своей статье: «Личное знакомство болгарских ученых с Б. Г. Ананьевым состоялось впервые в 1945 году, во время учредительной научной сессии АПН РСФСР, в работе которой приняли участие и иностранные делегаты. Болгарскую сторону представляли профессора психологии и педагогики - Генчо Пирьов и Тодор Самодумов» (Няголова, 2017: 215). В начале 1970-х г. Генчо Пирьов несколько раз приезжал в Ленинград, общался с ленинградскими психологами и выступал на факультете психологии.

${ }^{2}$ Судя по документам личных дел Ананьева и Мясищева, а также протоколам заседаний кафедры начала 1950-х складывается впечатление о переходном периоде в смене руководства кафедрой. Протоколы подписывал Борис Герасимович, а в Личном деле он указывает на свою новую должность директора НИИ педагогики. Заявление Ананьева о переходе из должности заведующего в должность профессора кафедры подписано ректором А.Д. Александровым 20 июня 1953 г. В личном деле Владимира Николаевича заведование точно никак не обозначено. Там написано, что с 1939 г. до 1961 он работал директором Психоневрологического института и заведовал кафедрой психологии в ЛГУ.
} 
Научные труды Московского гуманитарного университета

2019 № 1

ствия с кафедрой и отделением психологии, продолжал руководить студенческими и аспирантскими научными работами, организовывал совместные с НИИ педагогики исследования и конференции. Сотрудничество и соратничество Ананьева с Мясищевым продолжалось до конца жизни. Но для Мясищева главным полем деятельности был Психоневрологический институт им. В. М. Бехтерева, директором которого он был около двадцати лет.

В годы заведования кафедрой (1953-1960) В. Н. Мясищев опубликовал книгу «Личность и неврозы» (1960), двухтомник «Психические особенности человека» (1957 и 1960 гг. в соавторстве с А. Г. Ковалевым), ряд важных статей. Под его руководством кафедра усиленно занималась проблемой личности, потребностей, общения и межличностных отношений.

Как писал А. А. Бодалев, «в конце 50-х - начале 60-х гг. В. Н. Мясищев один из первых в отечественной психологии ввел в практику повседневной научно-исследовательской психодиагностической работы использование новых методов изучения личности, в том числе и тех, которые были разработаны за рубежом. В. Н. Мясищев не только допускал применение зарубежных методик, но в ряде случаев считал их использование необходимым» (Бодалев, 1995: 12). Владимир Николаевич много сделал для развития медицинской (клинической) психологии как в Ленинграде, так и в масштабе страны, возглавив созданную в 1963 г. по его инициативе проблемную комиссию «Медицинская психология» при Академии медицинских наук СССР.

Первые два десятилетия существования кафедры психологии в ЛГУ стали новым этапом развития Петербургской психологической школы, центральным звеном которой явилась Ленинградская школа, или школа Ананьева ${ }^{1}$. Подводя итоги развития психологического отделения, в обосновании возможности и необходимости открытия факультета психологии Б. Г. Ананьев писал о том, что по своему значению психологическое отделение стало центром человекознания в Ленинградском университете и поэтому естественна его роль как посредника между гуманитарными и естественными (особенно биологическим) факультетами (Ананьев, 1965). Благодаря этому стали возможны комплексные исследования человека в целях психологического познания по программе Б. Г. Ананьева, которые дали значительные результаты и повлияли на методологию и теорию психологии в России.

Благодаря подвижническому труду Бориса Герасимовича Ананьева и его соратников психологический научно-образовательный центр - отделение и затем факультет психологии Ленинградского государственного университета - стал ядром Ленинградской и главным звеном всей Петербургской психологической школы.

\footnotetext{
${ }^{1}$ Ныне, спустя годы (теперь уже более 40 лет) после ухода из жизни ее основателя, закономерно говорить о послеананьевском периоде. Его изучение и осмысление, а тем более объективная оценка - дело будущих исследователей истории науки.
} 


\section{СПИСОК ЛИТЕРАТУРЫ}

Ананьев, Б. Г. (1965) Психологическая школа Ленинградского университета // Вестник Ленинградского университета. Серия: Философия, экономика, право. Вып. 1. № 5. С. 79-86.

Бодалев, А. А. (1995) В. Н. Мясищев и психология отношений // Мясищев В. Н. Психология отношений. Избранные психологические труды. М. : Московский психолого-социальный институт ; Воронеж: «МОДЭК». С. 5-14.

История Ленинградского Университета. 1819-1969. Очерки (1969). Л.: Изд-во Ленинградского университета.

Кольцова, В. А., Олейник, Ю. Н. (2006) Советская психологическая наука в годы Великой Отечественной войны (1941-1945). М. : Московский гуманитарный университет; Институт психологии РАН. 360 с.

Логинова, Н. А. (2006) «Русский путь» ученого: XX век // Борис Герасимович Ананьев: Биография. Воспоминания. Материалы / автор и сост. Н. А. Логинова. СПб. : Изд-во С.-Петербур. ун-та.

Логинова, Н. А. (2014) Центр научного человекознания (70 лет со дня открытия отделения психологии Ленинградского государственного университета (СПбГУ) // Вестник ЛГУ им. А. С. Пушкина. Сер. Психологии и педагогики. Вып. 2. Т. 5. С. 70-80.

Логинова, Н. А. (2016) Антропологическая психология Бориса Ананьева. М. : Изд-во «Институт психологии РАН».

Научная конференция психологического отделения философского факультета (1945). Тезисы докладов. Л. : ЛГУ.

Няголова, М. Д. (2017) О влиянии психологической теории Б. Г. Ананьева на развитие болгарской психологии // История российской психологии в лицах: Дайджест-2017. № 2. С. 214-224.

Степанова, Е. И. (2003) Становление психологической школы Б. Г. Ананьева: Памятные даты и события. СПб. : Изд-во «Симпозиум».

Шемякин, А. Н. (1948). Дискуссия по вопросам истории русской психологии // Вестник Ленинградского университета. № 4. С. 137-139.

Дата поступления: 15.01.2019 г.

Логинова Наталья Анатольевна - доктор психологических наук, профессор, профессор кафедры психологии развития и дифференциальной психологии Санкт-Петербургского государственного университета; Лауреат премии им. С. Л. Рубинштейна РАН (2008); член Европейского научного сообщества по истории гуманитарных наук (ESHHS). Адрес: 199034, Россия, г. Санкт-Петербург, наб. Макарова, д. 6. Тел.: +7 (812) 328-94-20. Эл. адрес: developmental.psychology@spbu.ru 
Loginova Natalia Anatolyevna, Doctor of Psychology, Professor, Professor, Department of Developmental Psychology and Differential Psychology, Saint Petersburg State University, Laureate, S. L. Rubinstein RAS Prize (2008), Member, European Society for the History of the Human Sciences (ESHHS). Postal address: 6, Makarova Emb., Staint Petersburg, Russian Federation, 199034. Tel: +7 (812) 328-94-20. E-mail: developmental.psychology@spbu.ru

\section{Для цитирования:}

Логинова Н. А. Становление психологического образования и научных исследований по психологии в Санкт-Петербургском государственном университете: 1940-1950-е гг. [Электронный ресурс] // Научные труды Московского гуманитарного университета. 2019. № 1. URL: http://journals.mosgu.ru/trudy/article/view/933 (дата обращения: дд.мм. гг.). DOI: 10.17805/trudy.2019.1.6 